\title{
Trophic cascades in the western Ross Sea, Antarctica: revisited
}

\author{
David G. Ainley ${ }^{1, *}$, Grant Ballard2 ${ }^{2}$, Randolph M. Jones ${ }^{3}$, Dennis Jongsomjit ${ }^{2}$, \\ Stephen D. Pierce ${ }^{4}$, Walker O. Smith $\mathrm{Jr}^{3}$, Sam Veloz ${ }^{2}$ \\ ${ }^{1}$ H.T. Harvey \& Associates Ecological Consultants, Los Gatos, CA 95032, USA \\ ${ }^{2}$ Point Blue Conservation Science, Petaluma, CA 94954, USA \\ ${ }^{3}$ Virginia Institute of Marine Science, College of William \& Mary, Gloucester Point, VA 23062, USA \\ ${ }^{4}$ College of Earth, Ocean, \& Atmospheric Sciences, Oregon State University, Corvallis, OR 97331, USA
}

\begin{abstract}
We investigated mesopredator effects on prey availability in the Ross Sea, Antarctica, assessing the reasons why Adélie penguin Pygoscelis adeliae foraging trip duration (FTD) increases and diet changes from krill to fish as numbers of foraging penguins and competing cetaceans increase in the penguins' foraging area. To investigate penguins' seasonally changing FTD as a function of foraging-population size - previously investigated indirectly - we used bio-logging to determine the penguins' 3-dimensional foraging volume, while an autonomous glider quantified the depth, abundance, and distribution of potential prey. As numbers of foraging penguins and cetaceans increased, penguins spent more time on foraging trips, traveling farther and deeper, and their diet included more fish, as average maximum depth of krill increased from 45 to $65 \mathrm{~m}$, and that of small fish also deepened, but only from 51 to $57 \mathrm{~m}$. With a need to forage at greater depths for increasingly overlapping prey, the penguins consumed more of the energydense fish. Krill depth was negatively correlated with chlorophyll (a proxy for krill food), indicating an uncoupling between the two and the overwhelming importance of predation avoidance by the krill relative to food acquisition. Results support the hypotheses that (1) predators remove the grazers from Ross Sea surface waters, controlling their vertical distributions; and (2) the food web has a 'waspwaist' structure, in which middle- and upper-trophic levels are controlled top-down, whereas phytoplankton production and accumulation are regulated bottom-up, largely independent of grazer control. Ross Sea models need revision to reflect this food web structure.
\end{abstract}

*Corresponding author: dainley@penguinscience.com

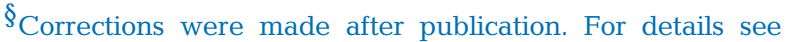
www.int-res.com/abstracts/meps/v534/c_p1-16/

This corrected version: September 14, 2018

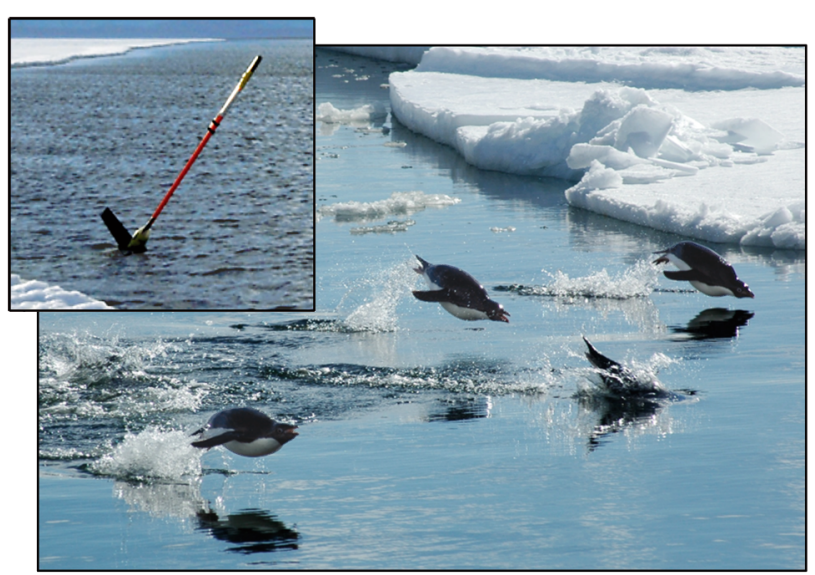

Adélie penguins returning from foraging; and the glider at Cape Crozier, Ross Island-nose down, antenna up-poised to begin quantification of penguin food.

Photos: D. Ainley and W. Smith

KEY WORDS: Adélie penguin · Foraging competition · Ross Sea $\cdot$ Trophic cascade $\cdot$ Wasp-waist food web structure

Resale or republication not permitted without written consent of the publisher

\section{INTRODUCTION}

Despite accumulating evidence (e.g. Sergio et al. 2014, Springer \& van Vliet 2014), the importance of top-down processes in structuring marine ecosystems remains under-appreciated (Terborgh \& Estes 2010, Estes et al. 2011). In part this is due to the large sizes of marine pelagic systems, which provide few opportunities for 'experiments' with which to eluci- 
date the importance of top-down forcing and trophic cascades (e.g. Myers et al. 2007, Heithaus et al. 2008, Wirsing et al. 2008, Estes 2014). As the capacity for top-down forcing declines due to upper-level predator removal (e.g. Jackson et al. 2001, Myers \& Worm 2003, Baum \& Worm 2009, Estes et al. 2011, Cheung et al. 2013), and as changes associated with climate modification increase (e.g. Thomas et al. 2004, Ainley et al. 2010, Cheung et al. 2013, Smith et al. 2014b), such systems will likely be increasingly difficult to study.

Evidence indicates that top-down forcing is important and measurable in the Ross Sea, Antarctica, among pelagic mesopredators and their prey (Testa et al. 1985, Ainley et al. 2006, Lyver et al. 2014), as well as among benthic communities (Dayton 1989, Pinkerton \& Bradford-Grieve 2014). The Ross Sea is the least anthropogenically affected continental shelf on Earth (Halpern et al. 2008); it still has substantial cetacean and other apex and mesopredator populations, and until recently has experienced little fishing (Ainley 2010, Ainley \& Pauly 2014). The effects on penguins of changing cetacean populations in decades past have been investigated (Ainley et al. 2007), as has the alteration in penguin foraging behavior in the presence of killer whales Orcinus orca and leopard seals Hydrurga leptonyx (Ainley \& Ballard 2012; see also Ainley et al. 2005). Environmental changes related to changing physical properties have been assessed (reduced salinity, increasing sea ice concentrations, and altered sea-ice season: Jacobs et al. 2002, Jacobs 2006, Stammerjohn et al. 2008, 2012), as have population responses by major mesopredators as exhibited by the penguins (Ainley et al. 2010, Lyver et al. 2014) and seals (Ainley et al. 2015). As a result, the Ross Sea remains an excellent system in which to investigate the relative roles of top-down and bottom-up forcing in a pelagic marine food web.

The Ross Sea is highly productive, supporting a food web having multiple trophic pathways (Smith et al. 2014a). Despite comprising just $2 \%$ of the Southern Ocean, the Ross Sea contributes an estimated $28 \%$ of its total primary production, as assessed by satellite-based models, and plays a significant role in the carbon budget of the Southern Ocean (Arrigo et al. 1998, 2008, Smith \& Comiso 2008). Consistent with this high primary productivity, the populations of the highest trophic levels are immense, e.g. $38 \%$ of the world's Adélie penguins Pygoscelis adeliae, 25\% of emperor penguins Aptenodytes forsteri, 30\% of Antarctic petrels Thalassoica antarctica, and substantial populations of marine mammals (Ballard et al. 2012, Smith et al. 2014a). However, the estimated standing stocks of middle trophic levels (herbivores such as copepods and krill; secondary consumers such as small fish) are surprisingly low, more than an order of magnitude lower, for example, than in the Scotia Sea (Deibel \& Daly 2007).

One hypothesis to explain the high productivitylow grazer biomass enigma is a trophic cascade in which mesopredators reduce the abundance of middle level organisms, resulting in much of the phytoplankton biomass being ungrazed (Arrigo et al. 2003, Ainley 2007, Smith et al. 2007, 2011b). This hypothesis is consistent with the substantial aggregate fluxes (Asper \& Smith 2003) and the large vertical fluxes of organic matter that have been found (Asper \& Smith 1999, Collier et al. 2000, Smith et al. 2011b); nutrient budgets indicate that vertical flux can be as much as $10 \%$ of the annual production (Sweeney et al. 2000, Smith et al. 2011b). Under this scenario, this surplus of ungrazed resources at the base of the trophic web is explained by a depressed abundance of grazers. This hypothesis would be amenable to ecosystem modeling, but without more knowledge of the key elements driving mid-trophic prey availability, the system is too poorly defined for an in-depth modeling approach. These modeling efforts are further complicated by the fact that many Ross Sea mesopredators prey on both crystal krill Euphausia crystallorophias, a major grazer of phytoplankton, and silverfish Pleuragramma antarcticum, a major predator of crystal krill (Eastman 1985, Ainley et al. 2003a, Ainley 2007, Pinkerton et al. 2013).

Studies of mesopredator foraging can help elucidate the tropic pathways in the absence of knowledge of exact prey distributions. Our research on the foraging of Adélie penguins from Ross Island, using tags that identify geographic position and diving activity (e.g. Lescroël et al. 2010, 2014, Ford et al. 2014), provides evidence supporting predator-driven tropho-dynamics - facilitated by extensive diet overlap among penguins and cetaceans (Ainley et al. 2006, Ballard et al. 2012) — though they likely forage differently (see Discussion). By investigating phytoplankton biomass and penguin prey abundance where penguins do and do not forage, we might better understand the spatial and temporal components of the trophic interactions that occur within the pelagic food web. Adélie penguins forage near some phytoplankton blooms but not others (V. Toniolo unpubl. data). Hence, on one hand, diatom production may lead to a 4-level trophic chain composed of primary, secondary and tertiary consumers (diatoms-krillfish-penguins). On the other hand, the production of colonial Phaeocystis antarctica, which dominates the 
phytoplankton during austral spring as well as on an annual basis (Smith et al. 2011b), may lead to a shorter trophic chain having only one known macroconsumer (pteropods), with a large portion of the Phaeocystis biomass being microbially remineralized within the water column (Smith et al. 2011a).

Ainley et al. (2006) presented 2 models based on some natural experiments during $8 \mathrm{yr}$ of study at 3 Ross Island Adélie penguin colonies of varying size, thus having co-varying radii of foraging 'halos' extending out from each (see Elliott et al. 2009, Ford et al. 2014 for a summary of the concept). In the first model, given that krill were replaced by fish in the diet over time during the breeding season, the prevalence of krill in the penguins' diet was explained by colony, time, and breeding population size (including both between- and within-colony size variation: a measure of intraspecific competition; Lewis et al. 2001). In the second model, penguins' foraging trip duration (FTD) was explained by colony, time, ice cover, and proportion of krill in the diet. When the prevalence of cetaceans was entered into these models, FTD was best explained by colony and the abundance of both Antarctic minke whales Balaenoptera bonaerensis (mainly a krill feeder) and fish-eating killer whales (ecotype C); prevalence of krill in the penguins' diet was best explained by colony and prevalence of minke whales. Penguin FTD was longer with larger colony sizes and when more whales were present (see also Ballance et al. 2009). On the basis of these results, foraging by penguins and whales appeared to alter the availability of fish and krill to penguins, at least over mesoscale spatial variations in the southwestern Ross Sea. In addition, the seasonally increasing FTD was at least partially due to an expansion over time of the foraging area at the large Crozier colony (Ainley et al. 2004, Ford et al. 2014). However, the question remained as to how these predators were altering prey availability: by interference competition, with whales driving krill deeper than the diving capability of penguins, or by exploitative competition via intra- and interspecific prey depletion.

We tested the opposing hypotheses that (1) predators remove the grazers from Ross Sea surface waters, controlling their vertical distributions and impacts on phytoplankton; versus (2) food availability for middle and upper trophic levels is regulated by bottom-up processes as a function of phytoplankton availability. To address these questions, we used an autonomous underwater vehicle (glider) equipped to assess both chlorophyll fluorescence and prey abundance (via acoustics), and deployed the glider at the same time and location where penguins were instrumented to elucidate foraging behavior (as in Ford et al. 2014). The study area was adjacent to one of the world's largest Adélie penguin colonies at Cape Crozier, Ross Island (280000 breeding pairs; Lyver et al. 2014); here penguins and cetaceans forage in the marginal ice zone of the Ross Sea Polynya (Dugger et al. 2014, Lescroël et al. 2014; Fig. 1). The Crozier colony also has a very extensive foraging 'halo,' much larger than the smaller colonies in the region, the size of the halo being a manifestation of the relative amount of prey depletion near to the colony (cf. Ainley et al. 2004, Ballance et al. 2009, Ford et al. 2014). We sought to learn whether increased FTD was due to a wider (farther from colony, longer duration spent foraging) and/or a more intensive (deeper diving) search for prey as prey became less available owing to predation pressure through time (Ainley et al. 2004, 2006). We predicted that we would observe longer distance and duration of penguin foraging trips and deeper diving as the penguin breeding season proceeded, and that there would be a correlated deepening of the main penguin prey species, also associated with the number of minke whales and killer whales in the study area. Both whale species are common in the area and can forage significantly deeper than the penguins (reviewed by Ballard et al. 2012).

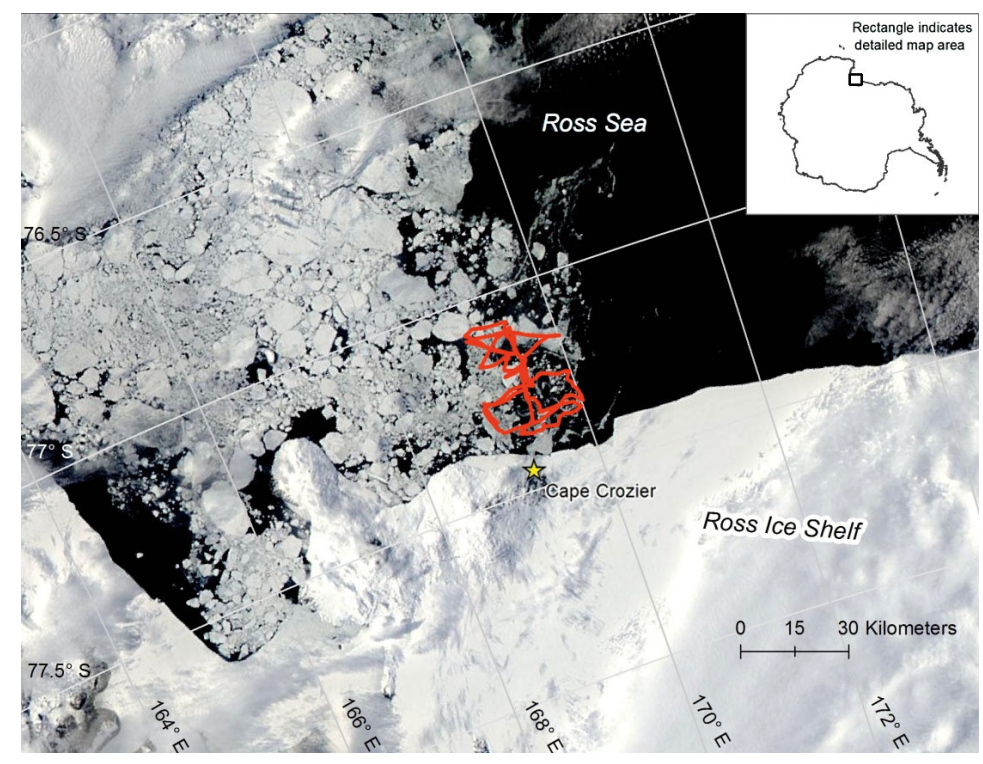

Fig. 1. Location of the glider track lines during the period when Adélie penguins Pygoscelis adeliae at the Cape Crozier colony (yellow star) were tagged to record foraging behavior, 10 December 2012 - 4 January 2013. Image depicts ice concentrations on 3 December 2012; courtesy NASA MODIS 


\section{MATERIALS AND METHODS}

\section{Data acquisition}

\section{Glider operations}

Gliders are buoyancy-propelled, autonomous underwater vehicles carrying instrumentation to collect physical and biological measurements on 'V-shaped' trajectories between surface and depth (e.g. Kaufman et al. 2014). With a fixed wing and no external moving parts, gliders navigate descending and ascending trajectories by shifting their center of mass on 2 axes and by varying the volume of oil in a buoyancy bladder external to the pressure housing. Vertical movement is typically at a speed of $\sim 25 \mathrm{~cm} \mathrm{~s}^{-1}$, and the glider typically travels ca. $2.5 \mathrm{~km}$ between each surfacing. Satellite communications with a remote base station occur when the glider is at the surface, allowing the glider to determine its position, transmit data to the base station, and obtain modified navigation and/or sampling commands. Our sampling utilized an iRobot 1KA Seaglider ${ }^{\mathrm{TM}}$ fitted with a SeaBird CT Sail, Aanderaa Oxygen Optode 4330F, and Wet Labs ECO Puck sensors, as well as an Imagenex 853 echo sounder. The glider was not allowed to move within $5 \mathrm{~km}$ of sea ice, as judged from satellite imagery, as gliders cannot surface under sea ice and maintain communication. Thus, the study area moved slightly west, sampling the adjacent open water as the marginal ice zone retreated.

The glider was deployed from the fast ice $\left(77.44^{\circ} \mathrm{S}\right.$, 169.75 ${ }^{\circ}$; Fig. 1) near Cape Crozier on 22 November 2012 at 09:25 h UTC. To obtain a full section across the marginal ice zone and its meltwater lens (see Smith \& Nelson 1985), the glider initially headed northeast for its first 50 dives before returning close to the point of deployment. For the remainder of the study, the glider followed a radiator pattern $(25 \times$ $50 \mathrm{~km}$ ), completing multiple passes along selected transects and continuously collecting data through $700 \mathrm{~m}$ (the mean depth in the study area). The transects were selected to cover the $95 \%$ minimum convex polygon of foraging penguins' at-sea locations previously determined using satellite telemetry for Cape Crozier (Ballard et al. 2010, Ford et al. 2014). Data were collected approximately every $5 \mathrm{~s}$; the Wet Labs ECO Puck and Imagenex 853 echo sounder were disabled below $250 \mathrm{~m}$ (200 m for the echo sounder after dive 53) to conserve battery power. The glider completed 571 dives over $78 \mathrm{~d}$ and was retrieved at $76.77^{\circ} \mathrm{S}, 167.73^{\circ} \mathrm{E}$ by the RVIB 'Nathaniel B. Palmer' (Cruise NBP12-10) on 8 February 2013 at 00:44 h UTC. A conductivity, temperature, and depth (CTD) calibration cast was completed upon recovery, and water samples were collected for chlorophyll and particulate organic carbon/ nitrogen determinations. Fluorescence voltages (FL) were converted into chlorophyll concentrations (CHL) using the regression $\mathrm{CHL}\left(\mu \mathrm{g} \mathrm{l}^{-1}\right)=0.00725 \times \mathrm{FL}+$ $0.371\left(R^{2}=0.71\right)$ determined from the calibration cast.

\section{Additional parameters derived from glider data}

Several physical and biological parameters were calculated or derived from the core data for various analyses and correlations (Table 1). Distance from the glider to Cape Crozier $\left(77.46^{\circ} \mathrm{S}, 169.25^{\circ} \mathrm{E}\right)$ was calculated using a great circle distance. Mixed layer depth (MLD) was computed using a potential density threshold method (Thomson \& Fine 2003), which defines the MLD as the minimum depth at which a $0.01 \mathrm{~kg} \mathrm{~m}^{-3}$ increase is observed over the value of $\sigma_{\theta}$ at $3 \mathrm{~m}$. Fluorescence measurements were processed by calibrating the sensor data with in situ bottle data collected at glider retrieval. Samples for chlorophyll a concentrations were analyzed by fluorometry using the acid-addition method on a Turner 10-AU fluorometer (JGOFS 1996). Glider measurements of fluorescence were converted to chlorophyll using the regression between fluorescence and extracted chlorophyll (Kaufman et al. 2014). Depth integrations of chlorophyll were calculated using trapezoidal integration.

\section{Acoustic data}

The glider-mounted Imagenex 853 echo sounder had a frequency of $120 \mathrm{kHz}, 10^{\circ}$ beam width, pulse length of $100 \mu \mathrm{s}$, a bin interval of $0.5 \mathrm{~m}$, and maximum range of $100 \mathrm{~m}$. The transducer source level was $210 \mathrm{~dB} \mu \mathrm{Pa}$ at $1 \mathrm{~m}$ and receiver sensitivity

Table 1. Mean (SD) values as observed by the glider in the Ross Sea, Antarctica, for the early (10-18 December 2012), middle (19-25 December), and late (26 December - 4 January) periods

\begin{tabular}{|lccc|}
\hline & Early & Middle & Late \\
\hline Sea surface temperature $\left({ }^{\circ} \mathrm{C}\right)$ & $-0.37(0.62)$ & $-0.22(0.65)$ & $0.02(0.46)$ \\
Sea surface salinity & $34.13(0.24)$ & $34.08(0.28)$ & $34.17(0.22)$ \\
$\begin{array}{l}\text { Integrated 0-50 m chlorophyll } \\
\left(\mathrm{mg} \mathrm{m}^{-3}\right)\end{array}$ & $14.5(4.0)$ & $11.6(3.1)$ & $8.4(1.7)$ \\
Mixed layer depth $(\mathrm{m})$ & $6(13)$ & $19(21)$ & $10(10)$ \\
\hline
\end{tabular}



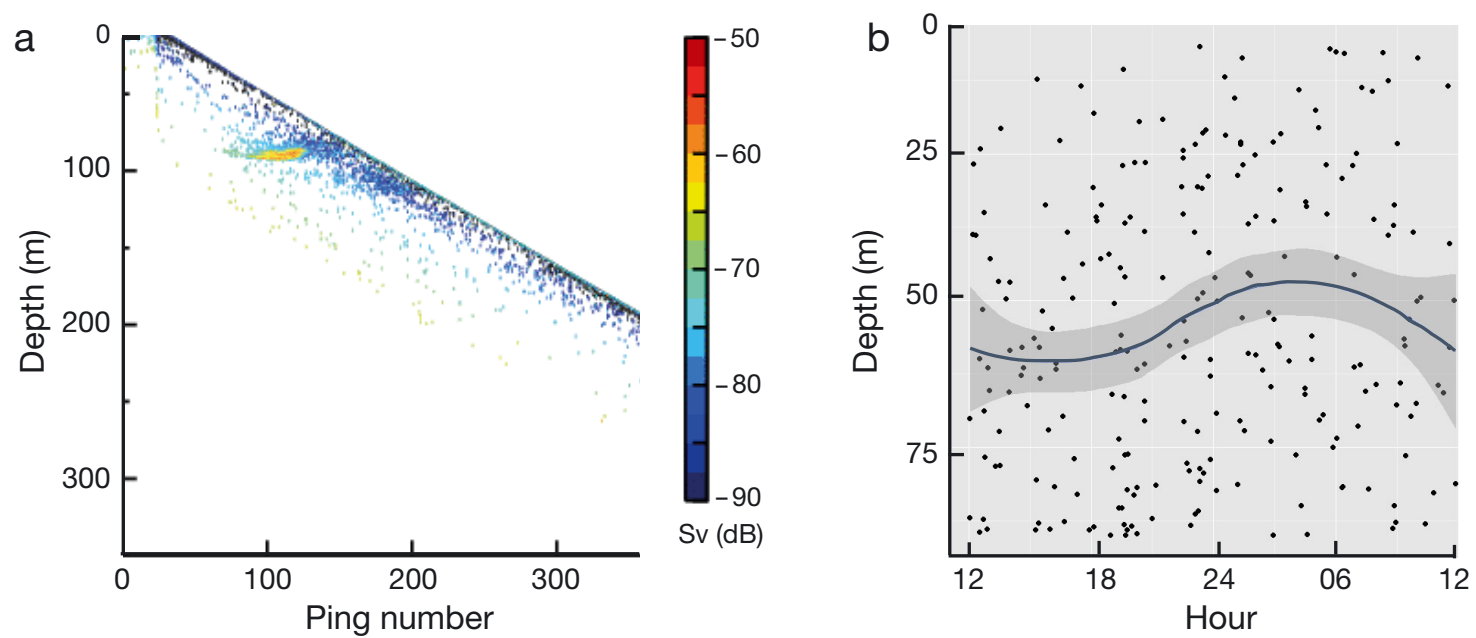

Fig. 2. (a) Krill swarm at $90 \mathrm{~m}$ as detected by the acoustic transducer on the glider. (b) Depth of krill swarms as a function of hour within the upper $90 \mathrm{~m}$ of the water column; the line is a smoothing spline $\pm 95 \% \mathrm{CI}\left(F_{2,237}=3.081, \mathrm{p}=0.048\right)$

$-180 \mathrm{~dB} \mathrm{~V}(\mu \mathrm{Pa})^{-1}$. It was operated in self-logging 'glider mode' with 1 ping every $4 \mathrm{~s}$ and a gain of $40 \mathrm{~dB}$. The raw binary format data were translated to ascii columns with the Linux command line program 'octal dump' (od -w256 --format=u1). Subsequent processing used these ascii data. Additional details about using the Imagenex 853 on a seaglider and obtaining volume backscatter from the instrument can be found in Guihen et al. (2014).

We characterized the background acoustic noise present in each echosounder profile and removed this noise prior to applying the time-varying-gain using the method of De Robertis \& Higginbottom (2007). The effective echosounder range, where signal was above the noise level, varied from about 50 to $75 \mathrm{~m}$. The echosounder was usually enabled only during downcasts when the glider depth was between 0 and $200 \mathrm{~m}$, so the typical depth range with acoustic data during a dive was 0 to $250 \mathrm{~m}$. The glider would typically move about $375 \mathrm{~m}$ horizontally during an acoustic measurement phase. The acoustic bin distances below the transducer were corrected for the effects of glider pitch and roll: these data were subsequently regridded into $1 \mathrm{~m}$ vertical ocean depth bins of mean volume backscattering strength $\left(S_{\mathrm{v}}\right.$, in $\left.\mathrm{dB}\right)$.

For each glider dive, the gridded $S_{\mathrm{v}}$ values were analyzed for krill aggregations. A krill aggregation was defined as a connected region in the acoustic matrix where all elements have $S_{\mathrm{v}}>-70 \mathrm{~dB}$, following Lawson et al. (2008) and Bernard \& Steinberg (2013). Data within $5 \mathrm{~m}$ of the ocean surface and within $1 \mathrm{~m}$ of the acoustic transducer were not included, as these are particularly biased by bubbles and other noise sources. The aggregation-detection method appeared to be effective in identifying krill swarms (e.g. Fig. 2). The non-krill acoustic signal at these frequencies was considered primarily to be silverfish, and the acoustic/trawling study of silverfish in the Ross Sea by O'Driscoll et al. (2011) suggests that this is a reasonable assumption. Bioacoustic sections were created for each of the 571 glider dives (e.g. Fig. 2). We examined data from the entire $250 \mathrm{~m}$ depth range of the glider, and calculated summary data for each dive from 0 to $90 \mathrm{~m}$ depth, where $97 \%$ of the acoustic backscatter was found.

\section{Investigation of Adélie penguin foraging/chick provisioning}

At the Cape Crozier colony (Figs. $1 \& 3$ ), breeding penguins arrive in late October; the females usually lay 2 eggs by mid-November, and chicks are fed from mid-December to early February. During the brooding and guard stages ( 10 to 31 December), one parent remains with the chick(s) while the other forages at sea. Nest reliefs occur every 1 to $3 \mathrm{~d}$. During the crèche stage (1 January to 15 February), chick caloric demands force both parents to forage simultaneously, thus, greatly increasing the foraging population: from about 380000 penguins foraging on any given day (considering foraging also by non-breeders who remain for long periods at their nests) to 660000 as the guard stage transitions to the crèche stage. Crèching in 2012-2013 began on 30 December. Our study period included all of the brood and guard stage and the early part of the crèche stage. We divided the study period into 2 halves for some analyses: 10 to 25 December is the 'early' chick-rearing period (one parent foraging) and 26 December to 4 January is the 

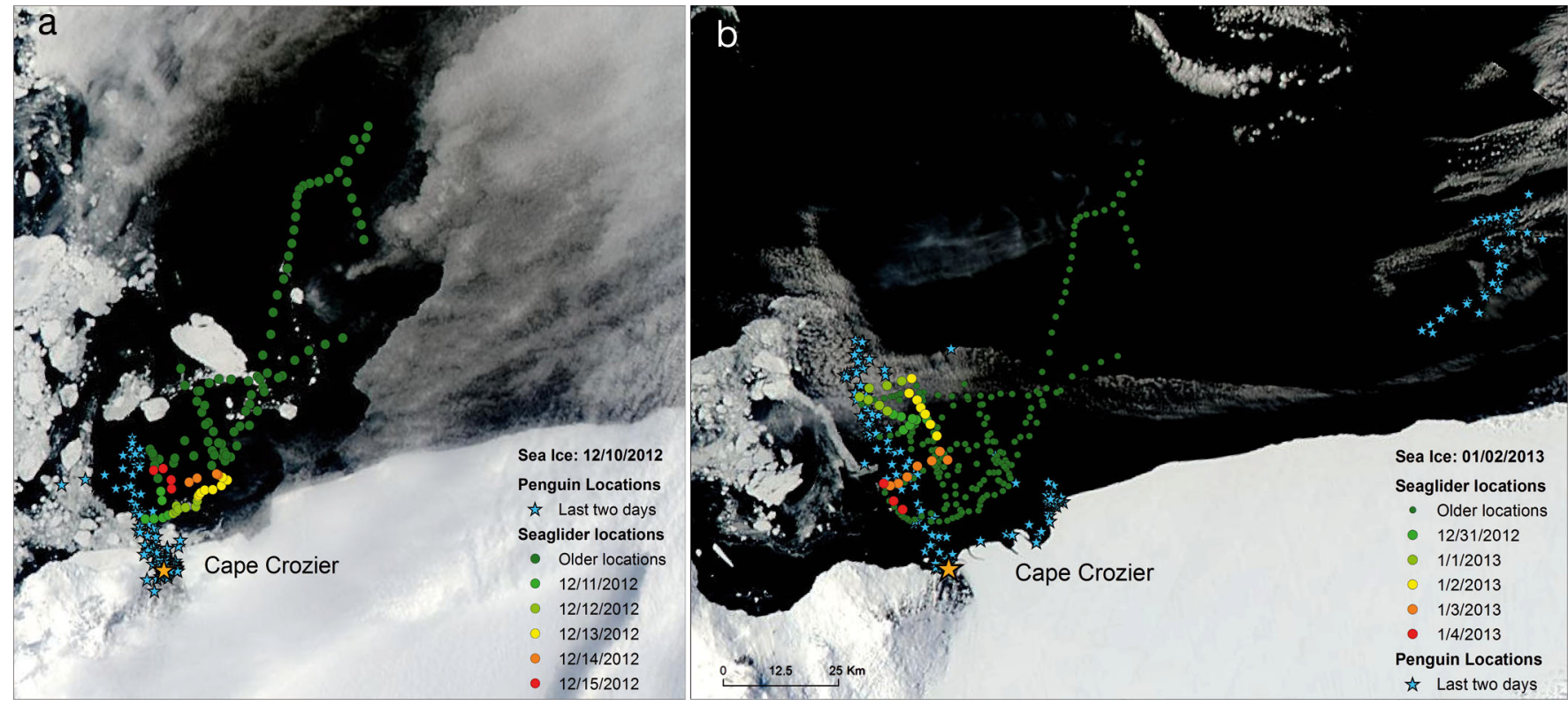

Fig. 3. Glider tracks, Adélie penguin Pygoscelis adeliae positions, and sea ice on (a) 10 December 2012, near the start of the early period ('older locations'), compared to (b) 2 January 2013, at the end of the late period. Last two days: (a) 16-17 December, and (b) 5-6 January

'late' chick-rearing period. In one subcolony, where foraging trip duration was measured using a weighbridge as described below, among 22 monitored nests (almost all members with radio frequency ID [RFID] tags), there were no chicks in the crèche stage on 10 , 15,20 , and 25 December, but by 31 December, 5 January, and 10 January, respectively, 5,28 , and $86 \%$ of nests had chicks in crèches.

Adélie penguins forage by diving, mostly at depths $\leq 50 \mathrm{~m}$ but to a maximum of $\sim 175 \mathrm{~m}$ (Whitehead 1989, Watanuki et al. 1997, Ainley \& Ballard 2011). During the study period, we equipped 46 adult birds, each having at least one chick, with 'Splash' tags (Wildlife Computers) that measure diving behavior as well as location. The first tag was applied on 10 December and the last one was removed on 4 January. The tags recorded depth, irradiance, and temperature every second; they weighed $62 \mathrm{~g}(1.6 \%$ of a $4 \mathrm{~kg}$ Adélie penguin) and had a cross-sectional area of $3.2 \times$ $10^{-4} \mathrm{~m}^{2}$ (1.0 to $1.6 \%$ of a penguin's cross-sectional area). One foraging trip was recorded for each equipped individual (46 trips, 35642 dives total). Attachment procedures are described by Ballard et al. (2001). Diving data were processed using the program Divesum (v.7.5.5; G. Ballard unpublished software). Divesum classified dives into 3 types: foraging, exploratory, and other by parameterizing several components of each dive (Chappell et al. 1993, Schreer et al. 2001, Lescroël et al. 2010, Ford et al. 2014): (1) dive duration (s); (2) maximum depth (m);
(3) depth change rate $\left(\mathrm{m} \mathrm{s}^{-1}\right.$; calculated as a running average for each $5 \mathrm{~s}$ block of the dive duration) in 2 categories: slow, i.e. $<1 \mathrm{~m} \mathrm{~s}^{-1}$, or fast, i.e. $>1.5 \mathrm{~m} \mathrm{~s}^{-1}$ (dives for which depth change rates $\geq 4 \mathrm{~m} \mathrm{~s}^{-1}$ were recorded were excluded because of likely instrument error); (4) rate of ascent and descent $\left(\mathrm{m} \mathrm{s}^{-1}\right.$; sustained rate of depth change in same direction from surface to bottom and from bottom to surface; bottom is any depth within $60 \%$ of the maximum depth reached on the dive); (5) bottom time (s) - the amount of time spent within $60 \%$ of the maximum depth and with no change in depth exceeding $0.5 \mathrm{~m} \mathrm{~s}^{-1}$; and (6) number of undulations. Foraging and exploratory dives both were at least $10 \mathrm{~m}$. Foraging dives had $\geq 4$ undulations and either had $\geq 15$ s bottom time, $30 \%$ of the dive duration spent in slow depth change rate and $30 \%$ with fast depth change rate, or $\geq 6$ undulations and rapid $\left(\geq 1 \mathrm{~m} \mathrm{~s}^{-1}\right)$ ascent/descent phases. Exploratory dives had $<4$ undulations or had $<15$ s bottom time and fewer than 6 undulations. All other dives were categorized as 'other' and are thought to be primarily traveling dives (see also Ford et al. 2014).

All satellite transmissions were processed within the Argos system (CLS Corporation). Satellite positions were filtered using the 'Argosfilter' package for R (Freitas 2012), which first removes all records with invalid locations (class Z), then all locations that require unrealistic swimming speeds (maximum $2.3 \mathrm{~m}$ $\mathrm{s}^{-1}$ ), and finally removes all spikes with angles $<15$ and $25^{\circ}$ if their extension is higher than 2500 and 
5000 m, respectively (Freitas et al. 2008). Because raw Argos positions are biased by satellite orbital parameters and the penguins' latitudinal positions (Georges et al. 1997), we used a linear interpolation algorithm (Tremblay et al. 2006) to create a temporally uniform distribution of locations every $15 \mathrm{~min}$ along each foraging track.

Because of the differences in temporal resolution between the dive (1 s) and location data (15 min, after interpolation), we used temporal proximity to assign an approximate geographic location to each dive. We assumed that the farther interpolated positions were in space and time from a known position (TKP), the greater was their positional error. Thus, we removed highly interpolated positions (>30 min TKP), which allowed more dives to be included in the analysis while reducing the locational errors.

Using a weighbridge (WB) across which penguins had to travel going to and from foraging trips (Ballard et al. 2010), we also measured FTD (h) of 40 breeding penguins with RFID tags from the start of Splash tag deployment until 20 January. Splash-tagged birds did not have RFID tags. We used the WB data for these (instead of the Splash data) for 2 reasons: (1) WB provided an independent estimate of FTD from a relatively large number of penguins per day, enabling a more complete basis for inferring colonywide patterns (e.g. Ballard et al. 2010, Lescröel et al. 2010, 2014); and (2) WB data were of higher temporal resolution because sampling was continuous, whereas Splash tag satellite positions are only available when Argos positions are available (on the order of every 1 to $6 \mathrm{~h}$ ). During this period, we also assessed the chicks' diet by observing the color and consistency of food boluses; pink paste was considered to be krill, and gray, more granular food was determined to be fish (Ainley et al. 2006, Whitehead et al. 2015). Diet observations were summarized to provide average proportion of krill vs. fish fed to chicks per day. We also logged the number of whales in the foraging area as described by Ainley et al. (2006) - i.e. binocular/telescope-aided observations made for $1 \mathrm{~h}$ twice per day from a coastal hill, $400 \mathrm{~m}$ a.s.l., effectively enabling a scan of $\sim 7 \mathrm{~km}$ out to sea.

\section{Data analysis}

2-dimensional kernel utilization distribution

To examine the 2-dimensional (2-D) space use of penguins, we developed 2-D utilization distributions (UDs) with only foraging locations as described above and a fixed-kernel density estimation (Worton 1989) using the 'adehabitatHR' package (Calenge 2006) in $\mathrm{R}$. The UD is the probability density that an individual is found at a given location. To visualize the UDs, we created 50, 75, and 95\% UDs for the early (10-25 December) and late (26 December - 4 January) periods for all individuals combined. Kernels were smoothed using the default 'href' method (Worton 1989).

\section{3-D kernel UD}

While satellite positional data allows us to track the horizontal space use of the penguins, dive data allow us to examine their 3-D space use and relate their positions to the 3-D (i.e. latitude, longitude, depth) distributions of phytoplankton and prey species as detected by the glider. To do this, we developed both 50 and 95\% 3-D penguin UDs. We included only foraging locations for all individuals combined and a 3-D kernel estimator using the 'ks' package (Duong 2013) in R. Kernels were smoothed using the default bandwidth selector (Gitzen et al. 2006, Duong 2007).

Following Simpfendorfer et al. (2012), we accounted for the uncertainty in our positional data by multiplying our smoothing factor by a value $>1$. To determine this multiplier, we calculated the 50 and 95\% UD and multiplied the smoothing factor by values from 1 to 10. We then determined the amount of change in the ratios between the 50 and $95 \%$ UDs for each multiplier value. The multiplier closest to the one with the smallest change was used (in this case, 3 ). We overlaid the glider-based krill and fish signals onto the penguin 3-D foraging plots for both the early and late periods.

\section{Statistical modeling}

We used linear regression to evaluate factors correlated with penguin foraging distance and depth. First, we used a mixed-effects generalized linear model to assess the effect of time in season (day of year) on FTD from the WB data, controlling for penguin identity as a random effect and sex as a fixed effect (males make shorter duration trips than females; Ballard et al. 2001, 2010).

Similar to the FTD analysis described above, we evaluated the effect of study day (10 December 4 January) on penguin maximum foraging distance (MFDi, $\mathrm{km}$; distance to farthest foraging location from Cape Crozier) as determined from the Splash 
tags, controlling for penguin identity as a random effect. MFDi was square-root transformed prior to the analysis to ensure normality of residuals. We were unable to directly assess the distance of prey from Cape Crozier as an explanatory variable in the FTD and MFDi models because the glider did not have sufficient location sampling frequency at the range of distances required to match the penguin behavior.

We also assessed factors influencing the maximum depth of foraging by penguins, including the halfday $(12 \mathrm{~h})$ mean depth of prey (krill and fish; see below), chlorophyll concentration, and study day, predicting that the foraging depth of the penguins would correlate with the mean prey depth, and that as the season progressed and prey were depleted, this correlation would grow stronger (i.e. the interaction between study day and depth of prey would be significant because prey would be increasingly less available). We included a factor for 'day' (04:00 to $21: 00 \mathrm{~h}$ local time) and 'night' (22:00 to $03: 00 \mathrm{~h}$ local time) among predictors in the model, as foraging behavior of penguins can be sensitive to irradiance levels in the water column (Ainley \& Ballard 2012). Note that photoperiods were $24 \mathrm{~h}$ during the entire study, but local light levels varied by time of day, with lowest levels during the 'night' period described above (sun level lowest, and behind the high mountains of Ross Island; G. Ballard \& D. Ainley pers. obs.). As above, we included a random effect for individuals in the analysis to account for the repeated sampling of each penguin during each foraging trip. We used day/night means in this analysis because this was the highest temporal resolution for which we could achieve a good match between sampling efforts of the glider and the penguins and also evaluate effect of light level associated with time of day in the model.

We used the 'Imer' function in the 'Ime4' package (Bates et al. 2014) in $\mathrm{R}$ to conduct the mixed-effect model analyses and a Type III Wald F-test with Kenward-Roger degrees of freedom to test the statistical significance of the fixed effects of the depth model using the ANOVA function in the 'car' package (Fox \& Weisberg 2011) in $R$, and the goodness of fit was assessed with the marginal ${ }^{2}$ GLMM 'R2GLMM(m)' of the model and the conditional $\mathrm{R}^{2} \mathrm{GLMM}$ of the model 'R2GLMM(c)' (Nakagawa \& Schielzeth 2013). All continuous explanatory variables in the penguin depth model were standardized to mean and unit variance prior to the analysis.

We evaluated factors affecting krill and fish depth as determined by the glider (described above) using linear models with a stepwise AIC reduction approach, considering the effects of study day, concentrations of chlorophyll in the upper $50 \mathrm{~m}$ of the water column, and distance of the glider from the Crozier colony. In the case of the fish depth model, we also tested krill depth as an explanatory variable (because the fish also eat the krill).

\section{RESULTS}

\section{Seasonal changes in bio-physical aspects of the study area}

Typical of the southwestern Ross Sea, ice concentrations decreased during the study period (Gloersen et al. 1992, Smith et al. 2014a), with spring concentrations being extensive immediately north of Ross Island and Cape Crozier but reduced to the east in the Ross Sea Polynya (Fig. 1). Ice concentrations decreased through summer, and sea ice largely disappeared north of Ross Island except for what remained directly to the north. Throughout, however, the marginal ice zone of the polynya existed within the study area extent.

Mixed-layer chlorophyll concentrations were maximal during mid-December and approached $20 \mathrm{mg}$ $\mathrm{m}^{-3}$, but decreased rapidly in early January (Table 1, Fig. 4). Spatial variability was observed, but this was far less than the temporal variability found over the entire spring-summer season. Sea-surface temperature was higher towards the end of the penguin instrument deployment period, perhaps owing to fewer wind and mixing events in that time and

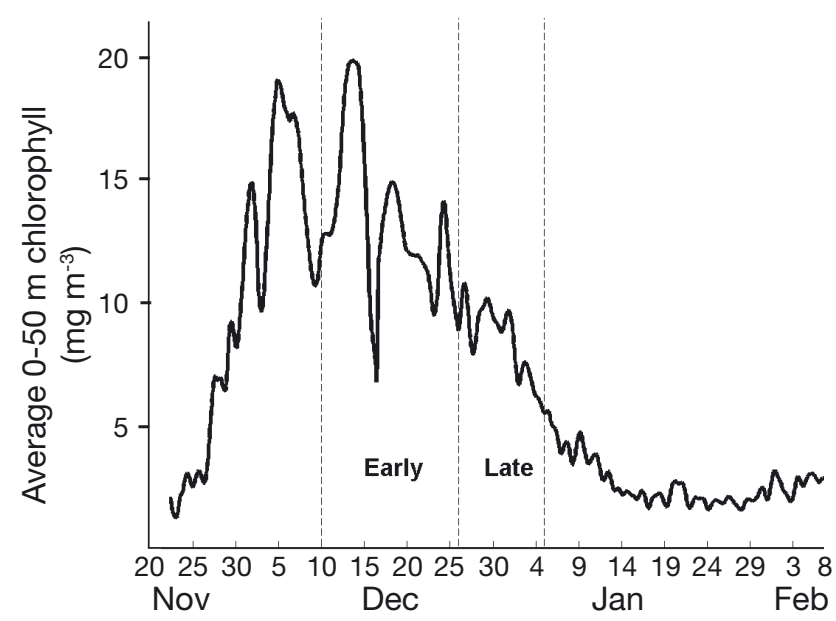

Fig. 4. Chlorophyll concentrations in the study area, 22 November 2012 to 8 February 2013: average chlorophyll $\left(\mathrm{mg} \mathrm{m}^{-3}\right)$ in the upper $50 \mathrm{~m}$ 
increased solar heating of the mixed layer. Surface salinity and MLD showed only modest changes, indicating our success in keeping the glider at the same position relative to proximity to sea ice in the marginal ice zone throughout the penguin instrument deployment period.

\section{Seasonally changing penguin foraging behavior}

FTD as determined by the WB remained relatively constant during the early period, but began to increase thereafter. Within the entire study period, FTD increased at about $1 \% \mathrm{~d}^{-1}(\beta=0.01 \pm 0.003, \mathrm{p}<$ 0.001; Fig. 5a) after controlling for significant effects of sex (FTD of males was $16 \%$ shorter than that of females; $\beta=0.16 \pm 0.07, p=0.02$ ). MFDi also increased throughout the study $(\beta=5.80 \pm 0.96, \mathrm{p}<$ $0.0001, R^{2}=0.46$; Fig. 5b). On 11 December, observed and predicted MFDi was $<25 \mathrm{~km}$ from the colony. Observed MFDi peaked at $146 \mathrm{~km}$ on 2 January (when the mean was $53.8 \mathrm{~km}$ ), while predicted mean MFDi increased to $63 \mathrm{~km}$ by 3 January.

Penguin chick diet at Cape Crozier was composed almost entirely of krill during the early period, but with the start of the late period, fish began to be eaten (Fig. 6). During the late period, fish contributed a third or more of the diet, similar to patterns described previously (Ainley et al. 2003a, 2006). The numbers of whales reached a maximum at the end of the early period and remained high into the late period (Fig. 7). However, since only about $6 \%$ of the penguin forag-
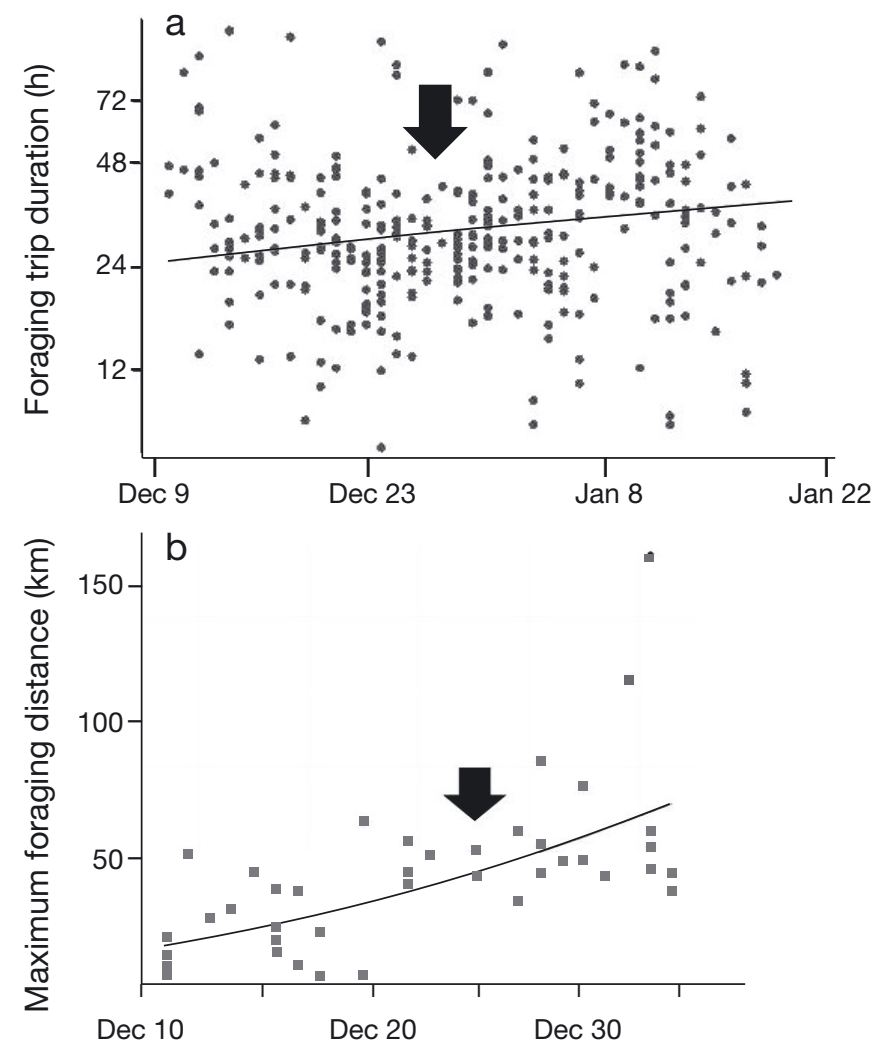

Fig. 5. (a) Foraging trip duration in hours (note scale of $y$ axis) of 40 breeding Adélie penguins Pygoscelis adeliae making 263 foraging trips at Cape Crozier, December 2012 to January 2013 (weighbridge data). Line shows predicted duration by date accounting for a fixed effect of sex and random effect of penguin identity. (b) Maximum foraging distance as determined from splash data. Arrows demarcate the end of the early and start of the late study period

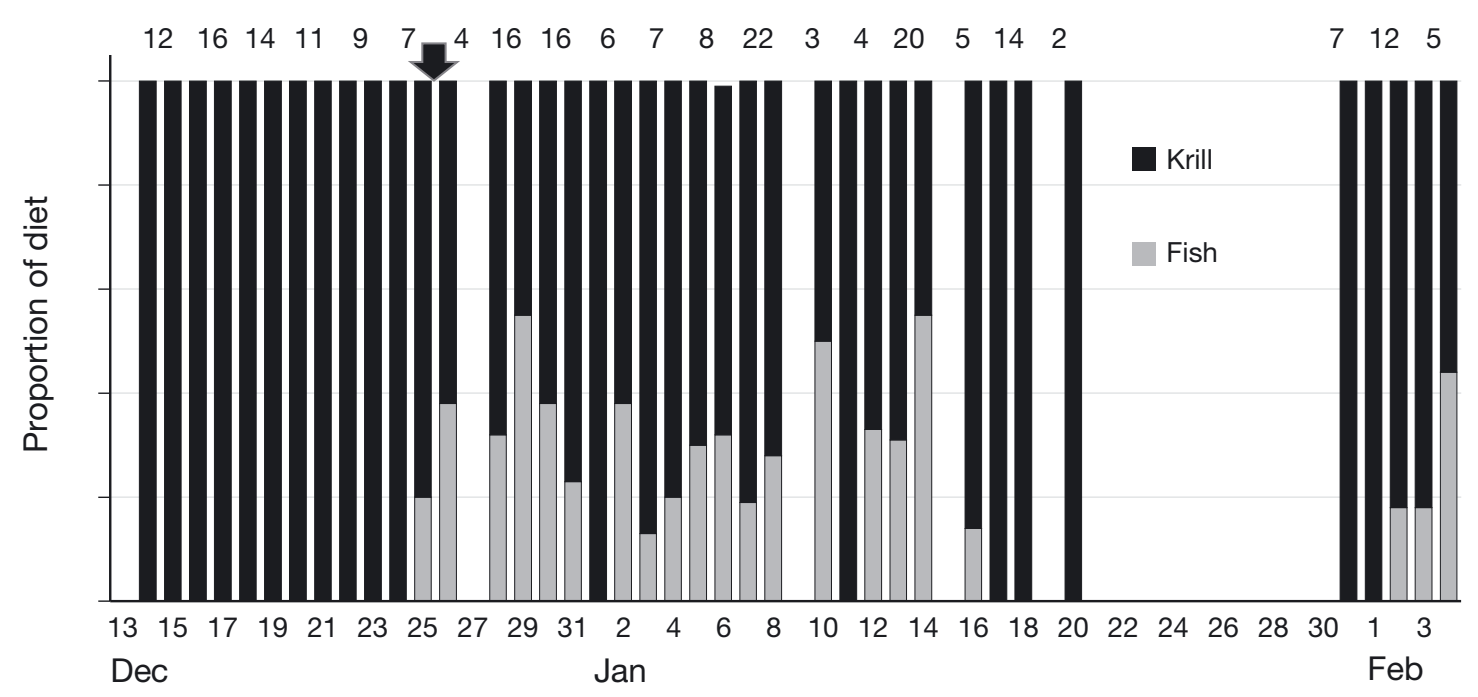

Fig. 6. Proportion of krill and fish in the diet of Adélie penguin Pygoscelis adeliae chicks at Cape Crozier, 14 December 2012 to 4 February 2013, based on methods of Ainley et al. (2006). The arrow demarcates the end of the early (26 December) and the beginning of the late period, which extended to 4 January. Numbers along top are $2 \mathrm{~d}$ sample sizes 


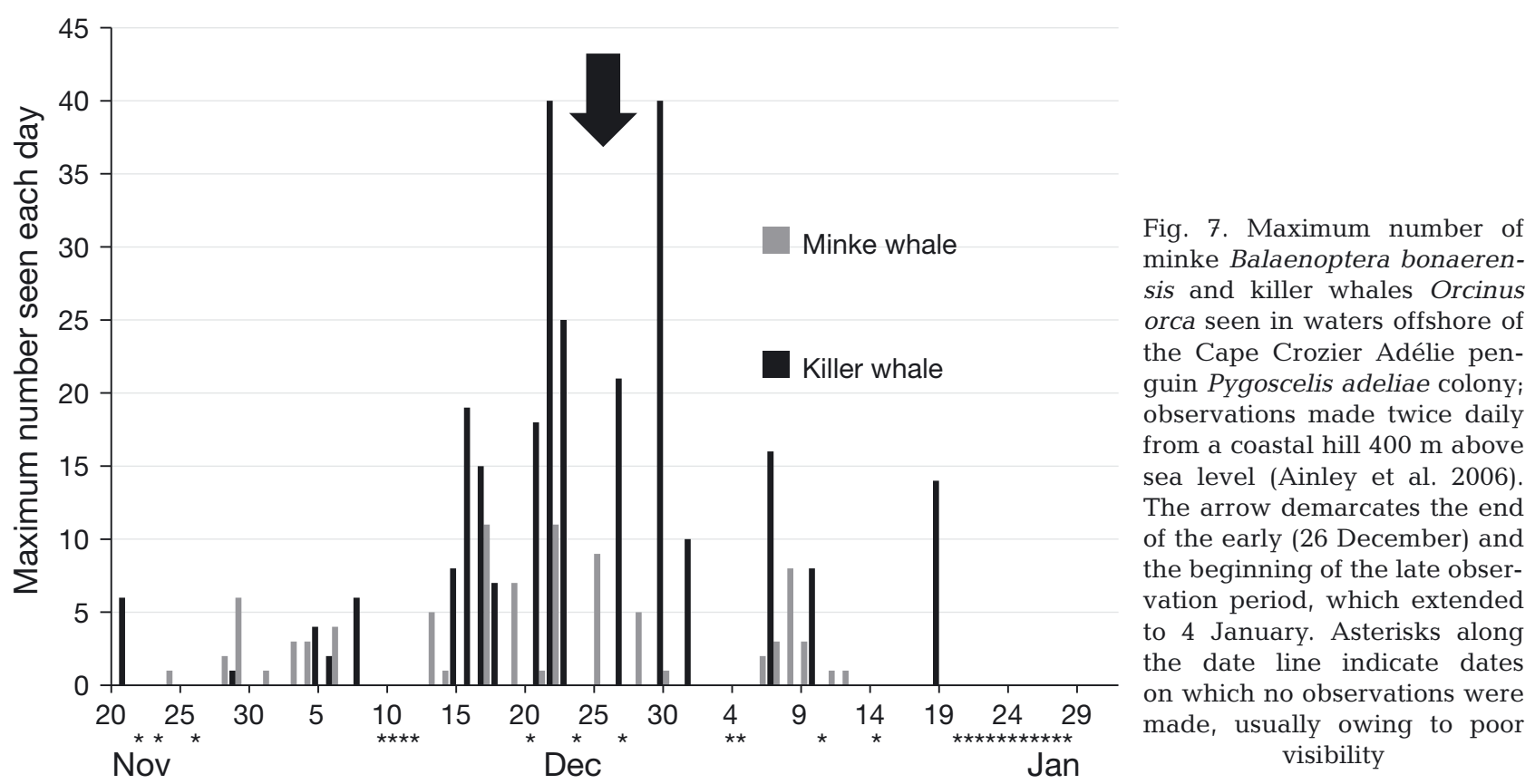

ing area could be seen from the whale observation point at Crozier (Ainley et al. 2006), it was not possible to know whether there was a decrease in number of whales foraging in the area or just that we could not see them as presumably, like the penguins, they moved to areas farther away and out of sight from Crozier. Therefore, we did not use whale numbers in the modeling.

\section{Penguin foraging behavior relative to prey availability}

Krill depth increased with study day, from $\sim 45$ to $\sim 65 \mathrm{~m}$, and fish depth also increased with study day (from $\sim 51$ to $\sim 57 \mathrm{~m}$; Fig. 8). The 46 Splash-tagged penguins made 35642 dives between 10 December and 4 January, of which 16675 (46.8\%) were classified as foraging. Both the 2-D UD maps (Fig. 9) and 3-D UD maps (Fig. 10) indicate that penguins had an expanded foraging area and volume in the late study period compared to the early period. Higherabundance prey detections tended to be, but were not exclusively, farther from the colony in the late period (Fig. 9).

During the early period, penguin diving depths ranged from near the surface to about $80 \mathrm{~m}$, completely overlapping the depth distribution of krill, but with fish near the bottom of the penguin foraging dives (Fig. 10a,c). During the late period, maximum krill abundance was near $70 \mathrm{~m}$, slightly deeper than the depths where fish occurred (Fig. 10b,d). This is reflected in the higher proportion of fish in the late period (see Fig. 6).

We found a significant increase in penguin foraging depth over time (Table 2, Fig. 10). All of the fixed effects in our model were significant predictors of foraging depth (marginal $\mathrm{R}^{2} \mathrm{GLMM}$ of the model = 0.338 and the conditional $\mathrm{R}^{2} \mathrm{GLMM}=0.640$ ). Study day (positive) and chlorophyll concentration (negative) had the strongest effect on penguin foraging depth. The effect of fish depth on penguin foraging depth varied through the study period; the effect of study day on penguin foraging depth was stronger when fish were at shallower depths than when fish were at deeper depths. Maximum penguin foraging depth was positively correlated to krill depth, and increasingly so later in the study (Table 2).

\section{DISCUSSION}

Our results showed that the change in diet and the increase in penguin FTD, as the intensity of predation pressure increased (more penguins foraging as more chicks entered the crèche phase, arrival of foraging whales), i.e. the importance of study day in the modeling, corresponded with an expansion of the foraging area (foraging farther from the colony; MTDi) and deeper diving. That is, the foraging volume increased over time. These changes were best explained as a response to reduction and deepening 
Fig. 8. Mean half-day depth of krill and fish within the upper $90 \mathrm{~m}$ of the water column vs. study day. The lines represent the regression predictions holding all other factors in the regressions at their mean value; the shaded areas indicate \pm 1 SE. The arrows demarcate the end of the early ( 26 December) period, which began 10 December, and the beginning of the late observation period, which extended to 4 January

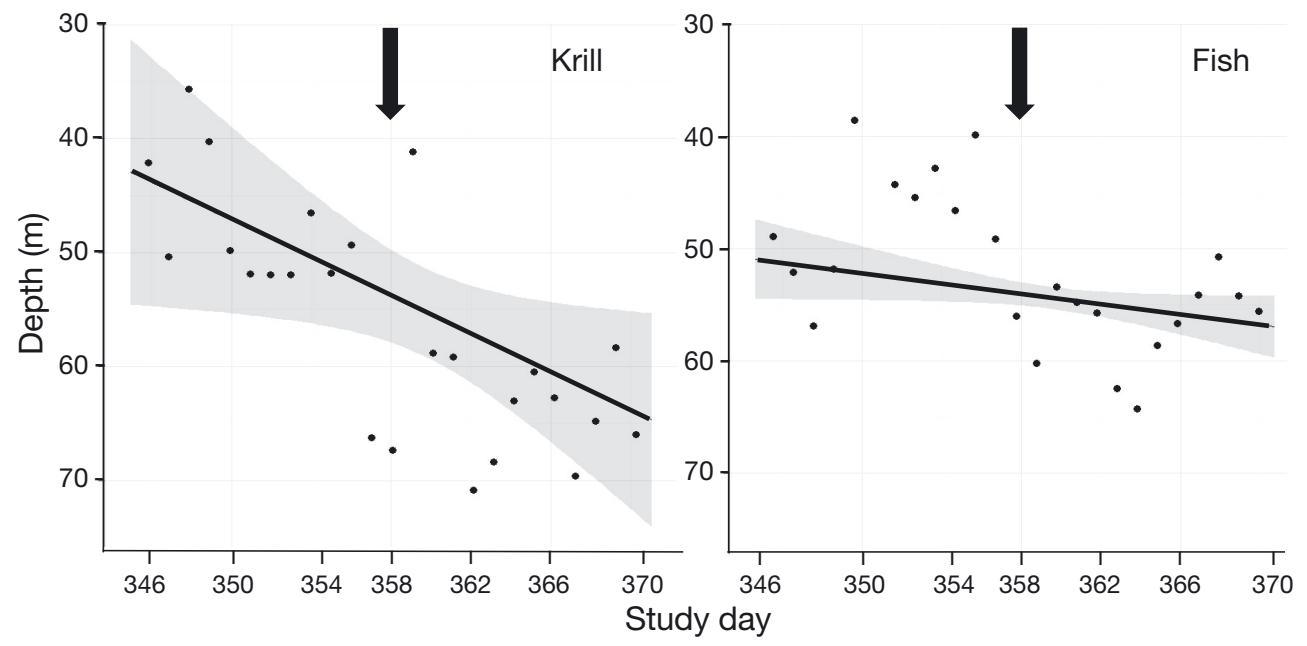

Fig. 9. Two-dimensional kernel utilization densities based on Adélie penguin Pygoscelis adeliae foraging locations (yellow circles); $(a, c)$ early period and $(b, d)$ late period together with krill $(a, b)$ and fish $(c, d)$ locations. Within the outer boundary of the foraging areas, intensity of penguin foraging density is depicted by color; dark brown: high ( $50 \%$ utilization distribution), light brown: intermediate ( $75 \%$ utilization distribution), gray: low ( $95 \%$ utilization distribution). Colored points indicate volume backscattering strength ( $S_{\mathrm{v}}$ ) of krill or fish (blue: low; green: intermediate; yellow: intermediate/high; red: high abundance) 


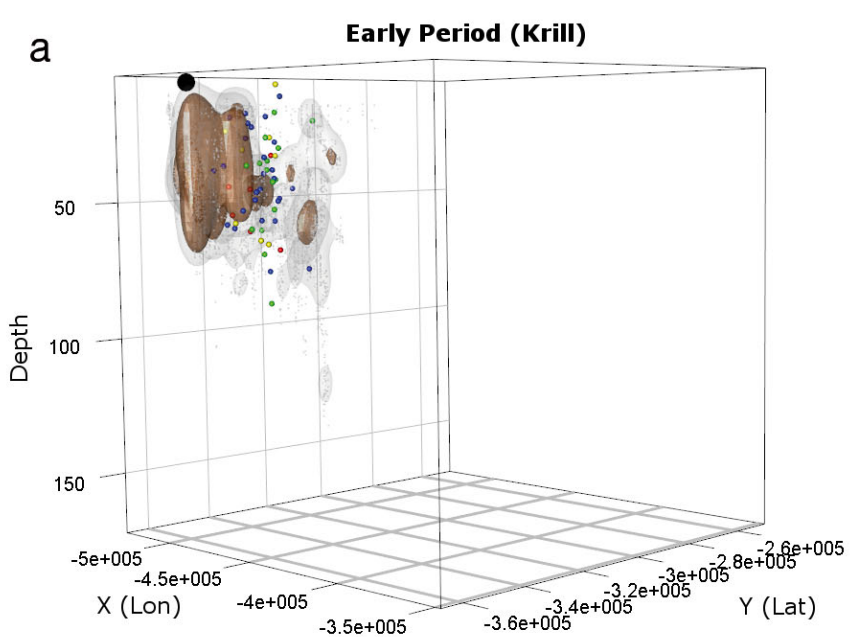

Early Period (Fish)

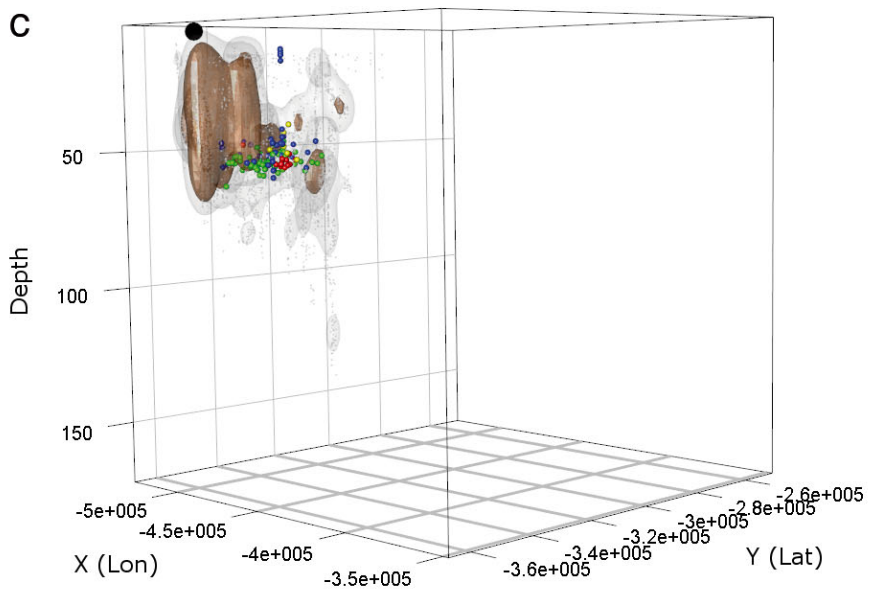

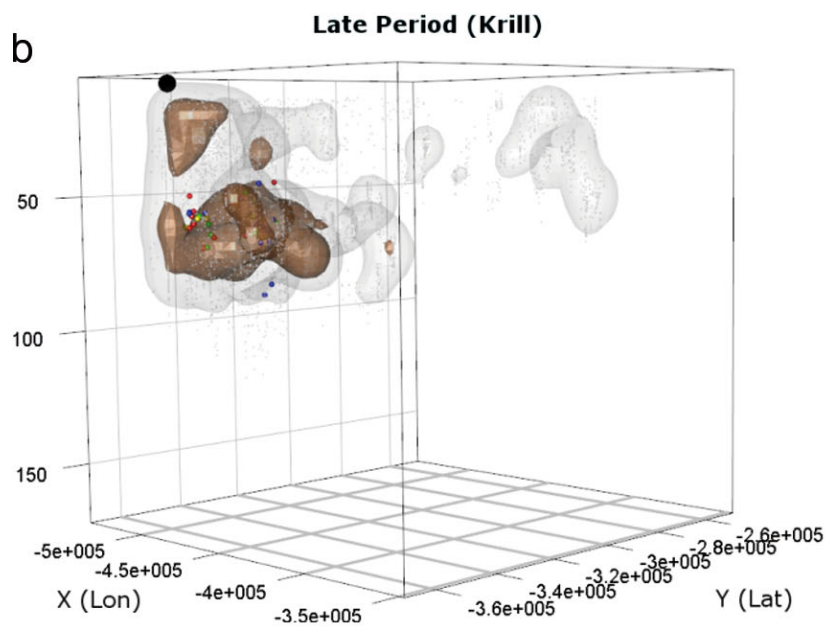

Late Period (Fish)

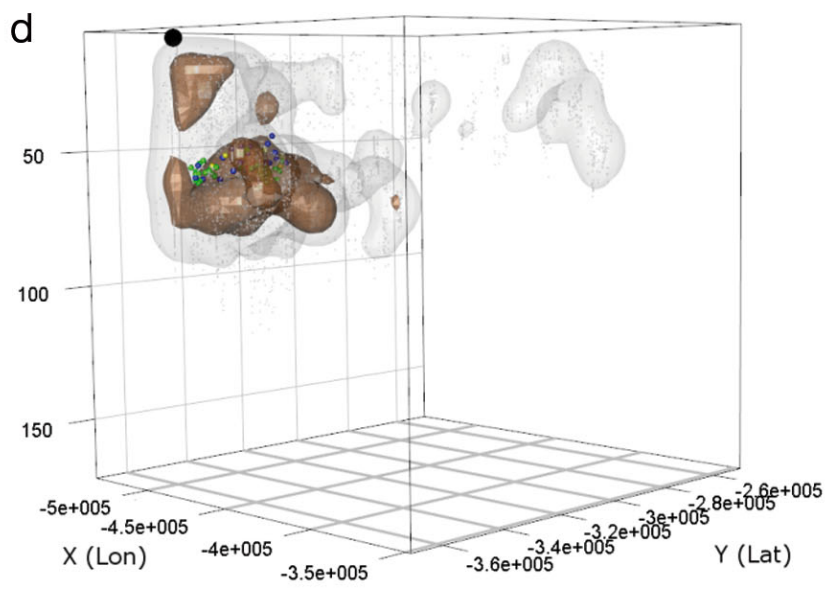

Fig. 10. Underwater side views (looking northwest) of the Adélie penguin Pygoscelis adeliae 3-dimensional utilization distributions together with $(\mathrm{a}, \mathrm{b})$ krill and $(\mathrm{c}, \mathrm{d})$ fish locations during the early $(\mathrm{a}, \mathrm{c})$ and late $(\mathrm{b}, \mathrm{d})$ periods. Depth axis $(\mathrm{z})$ in $\mathrm{m} ; \mathrm{longi-}$ tudinal axis $(x)$ extends $150 \mathrm{~km}$, latitudinal axis $(y) 100 \mathrm{~km}$ (cf. Fig. 1). Thicker grid lines are parallel to the depth plane; thinner gray lines are along the western-most plane. Colored points indicate volume backscattering strength $\left(S_{\mathrm{v}}\right)$ of krill or fish (blue: low, green: intermediate, yellow: intermediate/high, red: high abundance). Brown areas indicate higher penguin foraging density (50\% utilization distribution); gray areas indicate lower penguin density (95\% utilization distribution). The large black dot indicates the location of the Cape Crozier penguin colony

Table 2. Fixed effects results from a linear mixed model of Adélie penguin Pygoscelis adeliae foraging depth including individual penguin identity as a random effect. The values in parentheses in the estimate column are in the original units of the explanatory variables. The marginal $\mathrm{R}^{2} \mathrm{GLMM}=$ 0.338 and the conditional $\mathrm{R}^{2} \mathrm{GLMM}=0.640$

\begin{tabular}{|lccrrr|}
\hline Fixed effect & Estimate & SE & $F$ & df & $\mathrm{p}(>F)$ \\
\hline Krill depth & $-1.286(-0.072)$ & 0.271 & 22.594 & 1 & $<0.001$ \\
Fish depth & $2.488(0.806)$ & 0.264 & 88.740 & 1 & $<0.001$ \\
Study day & $6.735(1.01)$ & 1.092 & 37.276 & 1 & $<0.001$ \\
Mean chlorophyll 0-50 m & $-7.821(-2.477)$ & 0.398 & 385.729 & 1 & $<0.001$ \\
Day/night (night) & 0.3514 & 0.351 & 101.962 & 1 & $<0.001$ \\
Fish depth × study day & $-0.512(-0.025)$ & 0.228 & 5.041 & 1 & 0.025 \\
Krill depth × study day & $2.404(0.150)$ & 0.306 & 61.496 & 1 & $<0.001$ \\
\hline
\end{tabular}

of prey close to the colony. They are consistent with seasonal changes reported by Ainley et al. (2006) and confirmed those of Ford et al. (2014), who found that for penguins from the large Crozier colony, highest quality prey patches, as measured by penguin foraging intensity (increased density and frequency of diving), occurred farther from the colony over time.

Like surface-feeding seabirds (Lewis et al. 2001, Ainley et al. 2003b), intensive and deepening penguin foraging (i.e. subsurface diving birds) is correlated 
with reductions in prey availability at shallower depths. During chick-guarding (early period, 10-25 December; one parent foraging at a time), krill occurred in the upper water column. However, as predation pressure increased (both parents foraging, plus whales), the depth of the krill biomass maximum deepened significantly, as did that of silverfish, though only slightly. We suggest that once penguins began to forage at those greater depths, they began to encounter and take the deeper-dwelling fish that are a larger prey packet of significantly higher energy density than krill (5.2 vs. $4.6 \mathrm{kcal} \mathrm{g}^{-1}$; Ainley et al. 2003a), at least in part to compensate for greater energy expenditure during foraging (Ballance et al. 2009).

Unfortunately, we did not have bio-loggers on whales to learn how their foraging contributed to that of the penguins in altering the availability of prey within the penguin foraging area. One problem with bio-logging is that it assesses individual animals (e.g. Watanabe \& Takahashi 2013), although penguins forage in flocks of varying size often in synchrony (D. Ainley \& G. Ballard pers. obs. of penguins foraging in wide leads in McMurdo Sound and near the fast ice edge at Cape Crozier). Thus, the capacity of penguins to alter prey behavior/availability is not that of a single individual. How a penguin flock 'attacks' a prey school, especially in a possible coordinated way, remains unknown. More is known about the foraging tactics and prey response of Antarctic minke whales, which forage as individuals but have the capacity, owing to mouth size, to have a similar effect as a flock of penguins (e.g. Friedlaender et al. 2014). The depth of minke whale foraging is certainly affected by the depth of their prey and appeared to average well within our prey sampling zone to $90 \mathrm{~m}$ (Friedlaender et al. 2014), even if the depth at which prey (krill) aggregate in the presence of whales becomes deeper (Friedlaender et al. 2009). Unfortunately, the low density of the glider tracks precluded our ability to assess how mesopredator foraging might have altered the size and shape of prey schools/swarms.

All this is further evidence that within the Ross Sea food web, upper-level predators change the availability, if not the abundance, of grazers in surface waters during summer. While the total phytoplankton in the upper levels of the water column, including both the colonial haptophyte Phaeocystis as well as single-celled diatoms, showed a marked decrease over time, their concentration and consequent depth within the euphotic zone showed little change other than extreme episodic variations (likely induced by storm passages). Owing to the position of our study area at the open-ocean edge of the Ross Sea Polynya, as well as the time of season, most of the phytoplankton biomass was likely provided by Phaeocystis, which appears to be largely ungrazed by crystal krill, unlike diatoms (Smith et al. 2014a). Much of Phaeocystis sinks and sustains the Ross Sea benthic communities (Barry et al. 2003) or is remineralized within the water column (Smith et al. 2014a). Furthermore, the expected compositional changes in phytoplankton reflect a change from Phaeocystis dominance to diatom dominance after the abrupt decrease in Phaeocystis in late December (Smith et al. 2014a), as well as the overall decrease in biomass of all phytoplankton. The multiple simultaneous impacts of numerous trophic levels make the assessment of grazer impacts on diatoms difficult.

Our results, in conjunction with those of Ainley et al. (2006), show a close coupling between mesopredators and their prey in the marginal ice zone. The fact that krill depth increased as phytoplankton biomass decreased (suggesting an uncoupling between krill food and vertical distribution), along with the observation that penguins dove deeper presumably as they (and whales) drove krill deeper, further indicates an overwhelming importance of penguin (and other mesopredator) foraging in regulating krill distribution. Both penguin foraging depth and chlorophyll concentrations were strongly correlated to study day, which in our model is a proxy for changing predation pressure (seasonal increases in penguin foraging density and cetacean populations; see also Ainley et al. 2006). It is unlikely that the krill descended to feed on microzooplankton as phytoplankton standing stocks decreased, as going deeper puts them within the vertical distribution range of silverfish, a major crystal krill predator (Eastman 1985, Pinkerton et al. 2013); as the season progresses into autumn, the silverfish become cannibalistic, feeding on their own larvae (Eastman 1985), suggesting that this feeding response may result from krill becoming seasonally less available. We believe our results are one step closer to confirming the trophic cascade hypothesis; that is, predation pressure by mesopredators on appropriately-sized prey regulates their vertical distribution and abundance, which in turn uncouples the prey's impacts on their food items.

Together, the evidence we collected indicates that a 'wasp-waist' food web structure occurs in the Ross Sea, in which on the one hand top-down controls are most important to the upper and middle trophic levels of the pelagic communities (as opposed to the benthic; Barry et al. 2003, Pinkerton \& Bradford- 
Grieve 2014), but which are largely uncoupled from the immense bottom-up resource that the Ross Sea's phytoplankton provide. On the other hand, bottomup control of primary production is driven by both irradiance and micronutrients (Smith et al. 2014a) and is largely uncoupled from grazing. The apparent uncoupling of phytoplankton-mesozooplankton distributions, as well as the relative biomass levels, strongly suggest a lack of grazer control on primary production; however, a detailed assessment of the seasonal changes in all zooplankton and their relationship to phytoplankton is needed to fully test this relationship. These conclusions about food web structure are consistent with those of Frank et al. (2007), who found that 'wasp-waist' food webs predominate in more simple, cold-water continentalshelf ecosystems. Our results suggest that Ross Sea food web models based primarily on bottom-up processes, particularly when dominated by the Phaeocystis-based primary production (Pinkerton et al. 2010, Smith et al. 2011b), may not adequately capture the most important ecological interactions that have a major structural impact on the upper levels of the food web. Uncoupling between pelagic mesopredators and phytoplankton/primary production was also indicated by Dugger et al. (2014), who found no correlation between the substantial interannual variations in Ross Sea primary productivity (Arrigo et al. 2008, Smith \& Comiso 2008) and the productivity and breeding population size of penguins on Ross Island over the past 2 decades. Further research on the diatom- vs. Phaeocystis-based pelagic food webs and the top-down controls of middle trophic levels by mesopredators is warranted to better understand trophic cascades and food web structure in the Ross Sea (Smith et al. 2014a).

Acknowledgements. This project was supported financially by NSF grants ANT 1141948 and ANT 1142174, and logistically by the U.S. Antarctic Program, including helicopters to support glider deployment and the RV 'Nathaniel B. Palmer' for glider retrieval. Access to the Cape Crozier Specially Protected Area and work on penguins was approved under ACA Permit 2011-002 and Animal Welfare Permit 4130 through Oregon State University. V. Asper and K. Martin, University of Southern Mississippi, were instrumental in glider deployment and piloting; A. Pollard, E. Porzig, and S. Jennings helped to deploy and retrieve the Splash tags at Crozier. We acknowledge use of imagery from the Land Atmosphere Near-real time Capability for EOS (LANCE) system operated by the NASA/GSFC Earth Science Data and Information System (ESDIS) with funding provided by NASA/HQ. The manuscript benefitted from review by K. Dugger, A. Lescroël, and B. Saenz. This is VIMS contribution number 3492, and Point Blue Conservation Science contribution number 2038.

\section{LITERATURE CITED}

Ainley DG (2007) Insights from study of the last intact neritic marine system. Trends Ecol Evol 22:444-445

Ainley DG (2010) A history of the exploitation of the Ross Sea, Antarctica. Polar Rec 46:233-243

Ainley DG, Ballard G (2011) Non-consumptive factors affecting foraging patterns in Antarctic penguins: a review and synthesis. Polar Biol 35:1-13

Ainley DG, Pauly D (2011) Fishing down the food web of the Antarctic continental shelf and slope. Polar Rec 50: 92-107

Ainley DG, Ballard G, Barton KJ, Karl BJ, Rau GH, Ribic CA, Wilson PR (2003a) Spatial and temporal variation of diet composition and quality within a presumed metapopulation of Adélie penguins. Condor 105:95-106

Ainley DG, Ford RG, Brown ED, Suryan RM, Irons DB (2003b) Prey availability, interference competition, and the geographic structure of seabird colonies: a study of black-legged kittiwakes and forage fish in Prince William Sound, Alaska. Ecology 84:709-723

Ainley DG, Ribic CA, Ballard G, Heath S and others (2004) Geographic structure of Adélie penguin populations: size, overlap and use of adjacent colony-specific foraging areas. Ecol Monogr 74:159-178

Ainley DG, Ballard G, Karl BJ, Dugger KM (2005) Leopard seal predation rates at penguin colonies of different size. Antarct Sci 17:335-340

Ainley DG, Ballard G, Dugger KM (2006) Competition among penguins and cetaceans reveals trophic cascades in the Ross Sea, Antarctica. Ecology 87:2080-2093

Ainley DG, Ballard G, Ackley S, Blight LK and others (2007) Paradigm lost, or is top-down forcing no longer significant in the Antarctic marine ecosystem? Antarct Sci 19: 283-290

Ainley DG, Russell J, Jenouvrier S, Woehler E, Lyver PO, Fraser WR, Kooyman GL (2010) Antarctic penguin response to habitat change as earth's troposphere reaches $2^{\circ} \mathrm{C}$ above pre-industrial levels. Ecol Monogr 80:49-66

* Ainley DG, LaRue MA, Stirling I, Stammerjohn S, Siniff DB (2015) An apparent population decrease, or change in distribution, of Weddell seals along the Victoria Land coast. Mar Mamm Sci, doi:10.1111/mms.12220

Arrigo KR, Worthen D, Schnell A, Lizotte MP (1998) Primary production in Southern Ocean waters. J Geophys Res 103(C8):15587-15600

Arrigo KR, Worthen DL, Robinson DH (2003) A coupled ocean-ecosystem model of the Ross Sea: 2. Iron regulation of phytoplankton taxonomic variability and primary production. J Geophys Res 108:3231

* Arrigo KR, van Dijken GL, Bushinsky S (2008) Primary production in the Southern Ocean 1997-2006. J Geophys Res 113:C08004

Asper V, Smith WO Jr (1999) Particle fluxes during austral spring and summer in the southern Ross Sea (Antarctica). J Geophys Res 104:5345-60

Asper V, Smith WO Jr (2003) Abundance, distribution and sinking rates of aggregates in the Ross Sea Polynya. Deep-Sea Res I 50:131-150

Ballance LT, Ainley DG, Ballard G, Barton K (2009) An energetic correlate between colony size and foraging effort in seabirds, an example of the Adélie penguin Pygoscelis adeliae. J Avian Biol 40:279-288

Ballard G, Ainley DG, Ribic CA, Barton KR (2001) Effect of instrument attachment on foraging trip duration and nesting success of Adélie penguins. Condor 103:481-490 * Ballard G, Dugger KM, Nur N, Ainley DG (2010) Foraging 
strategies of Adélie penguins: adjusting body condition to cope with environmental variability. Mar Ecol Prog Ser 405:287-302

Ballard G, Jongsomjit D, Veloz SD, Ainley DG (2012) Coexistence of mesopredators in an intact polar ocean ecosystem: the basis for defining a Ross Sea marine protected area. Biol Conserv 156:72-82

Barry JB, Grebmeier JM, Smith J, Dunbar RB (2003) Oceanographic versus seafloor-habitat control of benthic megafaunal communities in the S.W. Ross Sea, Antarctica. Antarct Res Ser 78:327-354

Bates D, Maechler M, Bolker B, Walker S (2014) lme4: Linear mixed-effects models using 'Eigen' and S4. R package version 1.1-7. Available at http://CRAN.R-project.org/package $=$ lme 4

Baum JK, Worm B (2009) Cascading top-down effects of changing oceanic predator abundances. J Anim Ecol 78: 699-714

Bernard KS, Steinberg DK (2013) Krill biomass and aggregation structure in relation to tidal cycle in a penguin foraging region off the Western Antarctic Peninsula. ICES J Mar Sci 70:834-849

* Calenge C (2006) The package adehabitat for the R software: a tool for the analysis of space and habitat use by animals. Ecol Model 197:516-519

* Chappell MA, Janes DN, Shoemaker VH, Bucher TL, Maloney SK (1993) Reproductive effort in Adélie penguins. Behav Ecol Sociobiol 33:173-182

* Cheung WWL, Sarmiento JL, Dunne J, Frölicher TL and others (2013) Shrinking of fishes exacerbates impacts of global ocean changes on marine ecosystems. Nat Clim Change 3:254-258

* Collier R, Dymond J, Honjo S, Manganini S, Francois R, Dunbar R (2000) The vertical flux of biogenic and lithogenic material in the Ross Sea: moored sediment trap observations 1996-1998. Deep-Sea Res II 47:3491-3520

Dayton PK (1989) Interdecadal variation in an Antarctic sponge and its predators from oceanographic climate shifts. Science 245:1484-1486

De Robertis A, Higginbottom I (2007) A post-processing technique to estimate the signal-to-noise ratio and remove echosounder background noise. ICES J Mar Sci 64: 1282-1291

Deibel D, Daly KL (2007) Zooplankton processes in Arctic and Antarctic polynyas. In: Smith WO, Barber DG (eds) Polynyas: windows to the world's oceans. Elsevier, San Diego, CA, p 271-232

* Dugger KM, Ballard G, Ainley DG, Lyver PO, Schine C (2014) Adélie penguins coping with environmental change: results from a natural experiment at the edge of their breeding range. Front Ecol Evol 2:68

Duong T (2007) Kernel density estimation and kernel discriminant analysis for multivariate data in R. J Stat Softw 21:1-16

Duong T (2013) ks: Kernel smoothing. R package version 1.8.12. Available at http://CRAN.R-project.org/package=ks

Eastman J (1985) Pleuragramma antarcticum (Pisces, Nototheniidae) as food for other fishes in McMurdo Sound, Antarctica. Polar Biol 4:155-160

Elliott KH, Woo KJ, Gaston AJ, Benvenuti S, Dall'Antonia L, Davoren GK (2009) Central-place foraging in an Arctic seabird provides evidence for Storer-Ashmole's halo. Auk 126:613-625

Estes JA (2014) Commentary: salmon, seabirds, and ecosystem dynamics. Proc Natl Acad Sci USA 111:6534-6535

Estes JA, Terborgh J, Brashares JS, Power ME and others (2011) Trophic downgrading of planet Earth. Science
333:301-306

FFord RG, Ainley DG, Lescroël A, Lyver PO, Toniolo V, Ballard G (2014) Testing assumptions of central place foraging theory: a study of Adélie penguins Pygoscelis adeliae in the Ross Sea. J Avian Biol 46:193-205

Fox J, Weisberg S (2011) An $\{R\}$ companion to applied regression, $2^{\text {nd }}$ edn. Sage, Thousand Oaks, CA

Frank KT, Petrie B, Shackell NL (2007) The ups and downs of trophic control in continental shelf ecosystems. Trends Ecol Evol 22:236-242

Freitas C (2012) argosfilter: Argos locations filter. R package version 0.63. Available at http://CRAN.R-project.org/ package $=$ argosfilter

Freitas C, Lydersen C, Fedak MA, Kovacs KM (2008) A simple new algorithm to filter marine mammal Argos locations. Mar Mamm Sci 24:315-325

Friedlaender AS, Lawson GL, Halpin PN (2009) Evidence of resource partitioning between humpback and minke whales around the western Antarctic Peninsula. Mar Mamm Sci 25:402-415

Friedlaender AS, Goldbogen JA, Nowacek DP, Read AJ, Johnston D, Gales N (2014) Feeding rates and under-ice foraging strategies of the smallest lunge filter feeder, the Antarctic minke whale (Balaenoptera bonaerensis). J Exp Biol 217:2851-2854

Georges JY, Guinet G, Jouventin P, Weimerskirch H (1997) Satellite tracking of seabirds: interpretation of activity pattern from the frequency of satellite locations. Ibis 139: 403-405

Gitzen RA, Millspaugh JA, Kernohan BJ (2006) Bandwidth selection for fixed-kernel analysis of animal utilization distributions. J Wildl Manag 70:1334-1344

Gloersen P, Campbell WJ, Cavalieri DJ, Comiso JC, Parkinson CL, Zwally HJ (1992) Arctic and Antarctic sea ice, 1978-1987: satellite passive-microwave observations and analysis. NASA SP-511. National Aeronautics and Space Administration, Washington, DC

* Guihen D, Fielding S, Murphy EJ, Heywood KJ, Griffiths G (2014) An assessment of the use of ocean gliders to undertake acoustic measurements of zooplankton: the distribution and density of Antarctic krill (Euphausia superba) in the Weddell Sea. Limnol Oceanogr Methods 12:373-389

Halpern BS, Walbridge S, Selkoe KA, Kappel CB and others (2008) A global map of human impact on marine ecosystems. Science 319:948-952

* Heithaus MR, Frid A, Wirsing AJ, Worm B (2008) Predicting ecological consequences of marine top predator declines. Trends Ecol Evol 23:202-210

Jackson JBC, Kirby MX, Berger WH, Bjorndal KA and others (2001) Historical overfishing and the recent collapse of coastal ecosystems. Science 293:629-637

Jacobs S (2006) Observations of change in the Southern Ocean. Philos Trans R Soc Lond A Math Phys Eng Sci 364:1657-1681

Jacobs SS, Giulivi CF, Mele PA (2002) Freshening of the Ross Sea during the late $20^{\text {th }}$ century. Science 297:386-389

JGOFS (Joint Global Ocean Flux Study) (1996) Protocols for the Joint Global Ocean Flux Study (JGOFS) core measurements. Report No 19. Joint Global Ocean Flux Study, Sci Comm Oceanic Res, Int Counc Sci Unions, Intergovernmental Oceanographic Commission, Bergen

Kaufman DE, Friedrichs MAM, Smith WO Jr, Queste BY, Heywood KJ (2014) Biogeochemical variability in the southern Ross Sea as observed by a glider deployment. Deep-Sea Res I 92:93-106

Lawson G, Wiebe P, Stanton T (2008) Euphausiid distribu- 
tion along the Western Antarctic Peninsula-Part A: development of robust multi-frequency acoustic techniques to identify euphausiid aggregations and quantify euphausiid size, abundance, and biomass. Deep-Sea Res II 55:412-431

* Lescroël A, Ballard G, Toniolo V, Barton KJ, Wilson PR, Lyver PO, Ainley DG (2010) Working less to gain more: when breeding quality relates to foraging efficiency. Ecology 91:2044-2055

Lescroël A, Ballard G, Grémillet D, Authier M, Ainley DG (2014) Antarctic climate change: extreme events disrupt plastic response in Adélie penguins. PLoS ONE 9:e85291

Lewis S, Sherratt TN, Hamer KC, Wanless S (2001) Evidence of intra-specific competition for food in a pelagic seabird. Nature 412:816-819

Lyver PO, Barron M, Barton KJ, Ainley DG and others (2014) Trends in the breeding population of Adélie penguins in the Ross Sea, 1981-2012: a coincidence of climate and resource extraction effects. PLoS ONE 9:e91188

Myers RA, Worm B (2003) Rapid worldwide depletion of predatory fish communities. Nature 423:280-283

Myers RA, Baum JK, Shepherd TG, Powers SP, Peterson CH (2007) Cascading effects of the loss of apex predatory sharks from a coastal ocean. Science 315:1846-1850

* Nakagawa S, Schielzeth H (2013) A general and simple method for obtaining $\mathrm{R}^{2}$ from generalized linear mixedeffects models. Methods Ecol Evol 4:133-142

O'Driscoll RL, Macaulay GJ, Gauthier S, Pinkerton M, Hanchet S (2011) Distribution, abundance, and acoustic properties of Antarctic silverfish (Pleuragramma antarcticum) in the Ross Sea. Deep-Sea Res II 58:181-195

* Pinkerton MH, Bradford-Grieve JM (2014) Characterizing foodweb structure to identify potential ecosystem effects of fishing in the Ross Sea, Antarctica. ICES J Mar Sci 71: 1542-1553

Pinkerton MH, Bradford-Grieve JM, Hanchet SM (2010) A balanced model of the food web of the Ross Sea, Antarctica. CCAMLR Sci 17:1-31

Pinkerton $\mathrm{MH}$, Forman J, Bury SJ, Brown J, Horn S, O'Driscoll RL (2013) Diet and trophic niche of Antarctic silverfish Pleuragramma antarcticum in the Ross Sea, Antarctica. J Fish Biol 82:141-164

Schreer JF, Kovacs KM, O'Hara Hines RJ (2001) Comparative diving patterns of pinnipeds and seabirds. Ecol Monogr 71:137-162

Sergio F, Schmitz OJ, Krebs CJ, Holt RD and others (2014) Towards a cohesive, holistic view of top predation: a definition, synthesis and perspective. Oikos 123:1234-1243

Simpfendorfer CA, Olsen EM, Heupel M, Moland E (2012) Three-dimensional kernel utilization distributions improve estimates of space use in aquatic animals. Can J Fish Aquat Sci 69:565-572

Smith WO Jr, Comiso JC (2008) The influence of sea ice on primary production in the Southern Ocean: a satellite perspective. J Geophys Res 113:C05S93

Smith WO Jr, Nelson DM (1985) Phytoplankton bloom produced by a receding ice edge in the Ross Sea: spatial coherence with the density field. Science 227:163-166

Smith WO Jr, Ainley DG, Cattaneo-Vietti R (2007) Marine ecosystems: the Ross Sea. Philos Trans R Soc Lond B Biol Sci 362:95-111

Smith WO Jr, Asper V, Tozzi S, Liu X, Stammerjohn SE (2011a) Surface layer variability in the Ross Sea, Antarctica as assessed by in situ fluorescence measurements. Prog Oceanogr 88:28-45

Editorial responsibility: Scott Shaffer

San Jose, California, USA
Smith WO Jr, Shields AR, Dreyer J, Peloquin JA, Asper V (2011b) Interannual variability in vertical export in the Ross Sea: magnitude, composition, and environmental correlates. Deep-Sea Res I 58:147-159

* Smith WO Jr, Ainley DG, Arrigo KR, Dinniman MS (2014a) The oceanography and ecology of the Ross Sea. Annu Rev Mar Sci 6:469-487

* Smith WO Jr, Dinniman MS, Hoffman EE, Klinck J (2014b) Modeled impacts of changing winds and temperatures on the oceanography of the Ross Sea in the $21^{\text {st }}$ century. Geophys Res Lett 41:1624-1631

* Springer AM, van Vliet GB (2014) Climate change, pink salmon, and the nexus between bottom-up and top-down forcing in the subarctic Pacific Ocean and Bering Sea. Proc Natl Acad Sci USA 111:E1880-E1888

Stammerjohn SE, Martinson DG, Smith RC, Yuan X, Rind D (2008) Trends in Antarctic annual sea ice retreat and advance and their relation to El Nino-Southern Oscillation and Southern Annular Mode variability. J Geophys Res 113:C03S90

Stammerjohn SE, Massom R, Rind D, Martinson DG (2012) Regions of rapid sea ice change: an interhemispheric seasonal comparison. Geophys Res Lett 39:L06501

* Sweeney C, Hansell DA, Millero FD, Takahashi $\mathrm{T}$ and others (2000) Biogeochemical regimes, net community production and carbon export in the Ross Sea, Antarctica. Deep-Sea Res II 47:3369-3394

Terborgh J, Estes JA (2010) Trophic cascades: predators, prey, and the changing dynamics of nature. Island Press, Washington, DC

Testa JW, Siniff DB, Ross MJ, Winter JD (1985) Weddell seal-Antarctic cod interactions in McMurdo Sound, Antarctica. In: Seigfried WR, Condy PR, Laws RM (eds) Antarctic nutrient cycles and food webs. Springer, Heidelberg, p 561-565

* Thomas CD, Cameron A, Green RE, Bakkenes ML and others (2004) Extinction risk from climate change. Nature 427:145-148

Thomson RE, Fine IV (2003) Estimating mixed layer depth from oceanic profile data. J Atmos Ocean Tech 20: $319-329$

* Tremblay Y, Shaffer SA, Fowler SL, Kuhn CE and others (2006) Interpolation of animal tracking data in a fluid environment. J Exp Biol 209:128-140

*Watanabe YY, Takahashi A (2013) Linking animal-borne video to accelerometers reveals prey capture variability. Proc Natl Acad Sci USA 110:2199-2204

*Watanuki Y, Kato A, Naito Y, Robertson G, Robinson S (1997) Diving and foraging behaviour of Adélie penguins in areas with and without fast sea-ice. Polar Biol 17: 296-304

Whitehead AL, Lyver PO, Ballard G, Barton K and others (2015) Factors driving Adélie penguin chick size, mass and condition at colonies of differing size in the southern Ross Sea. Mar Ecol Prog Ser 523:199-213

Whitehead MD (1989) Maximum diving depths of the Adélie penguin, Pygoscelis adeliae, during the chick rearing period, in Prydz Bay, Antarctica. Polar Biol 9:329-332

* Wirsing A, Heithaus MR, Frid A, Dill LM (2008) Seascapes of fear: evaluating sublethal predator effects experienced and generated by marine mammals. Mar Mamm Sci 24: $1-15$

Worton B (1989) Kernel methods for estimating the utilization distribution in home-range studies. Ecology 70: $164-168$

Submitted: March 25, 2015; Accepted: June 12, 2015

Proofs received from author(s): August 24, 2015 